\title{
Developing pupils' critical thinking by teaching Mathematics
}

\section{Ovidiu BĂDESCU•, Cristian Stan•}

\section{Abstract:}

This article presents a research project on the development of critical thinking of 6th graders in Carass-Severin county using an educational program based on learning by discovery and problematisation. The first stage of the research consisting in diagnosing the of critical thinking level of development of $5^{\text {th }}$ graders in Carass-Severin county using a critical thinking test based on the Watson-Glaser model. We selected a representative lot of 542 pupils, taking into account the results of this test, the geographic distribution, the urban-rural environment, the teaching experience of the teaching staff teaching these pupils, then we sampled these pupils forming the experimental lot and the control lot, close in terms of critical thinking level. We elaborated, deployed and validated a training program "Developing Critical Thinking of Pupils by Teaching Mathematics", a training course offered by the Caras-Severin House of the Teaching Staff, the teachers participating in this course being those who taught the pupils in the experimental lot. After the completion of the intervention, the pupils in the two lots were tested again using the same type of tests, namely, Watson-Glaser, obtaining significant differences in favour of the experimental lot. We wanted to see if these abilities were stable over time and we applied a new test 3 months after the end of the intervention, and the conclusion was that the change was long-term, but also that the intervention created a series of abilities which pupils continue to use in order to improve their performances, even if the intervention was over. The interpretation of the results was done in SPSS using Mixed Bifactorial Variance Analysis (ANOVA) with Time asthe Within Subjects factor and Group asthe Between Subjects factor.

Keywords: critical thinking, learning by discovery, problematisation

\section{Delimitation of the research issues}

"Critical thinking is the use of those cognitive skills or strategies that increase the likelihood of a desired result [...] describes thinking that is deliberate, motivated, and purpose-oriented - a kind of thinking involved in solving problems, formulating conclusions, calculating probabilities, and making decisions...."(Halpern, 2003, p.6)

\footnotetext{
• Ovidiu Bădescu - Teacher, National College "Traian Lalescu" Reşiţa, PhD student Babes-Bolyai University, Cluj Napoca, badescuovidiu@yahoo.com

- Cristian Stan- Professor, PhD, Babes Bolyai University, Faculty of Psychology and Educational Sciences, Cluj-Napoca, cristiss2004@yahoo.com
} 
The critical thinking skills can be taught and learned. Experts mention that the most effective method of teaching them is the explicit and direct one. Pupils learn how to evaluate the credibility of a source of information and how to make content-independent decisions, which also makes it possible to transfer these skills to other themes and contexts. Like any abilities, these skills, once acquired, must be practiced. There is no better context for this than the educational context (Fischer, 2001).

There are studies that directly linked logic and critical thinking. Meyers (1986) shows that the study of logic does not seem to contribute to the development of the ability to think critically, but Bernstein, later on (1995), using informal logic to teach critical thinking, concluded that logic provides a powerful guideline in critical analysis of arguments, but does not help to harmonize competing arguments (Moon J., 2008, p.40).

We shallattemptthus to see to what extent the teaching of Mathematics through problematization and discovery leads to the improvement of pupils' critical thinking.

Unfortunately, in the school curriculum for the Mathematics subject approved by the Order of the Minister of Education and Research no. 3.393 of 28.02.2017, in force since the school year 2017-2018,this concept appears only twice, extremelyrarely compared to what society needs.

\section{Research design}

\section{Research purpose, objectives and duration}

The aim of our research is to test the level of pupils' critical thinking skills and to improve them by teaching maths with the help of problematisation and learning by discovery.

In compliance with its purpose, the research aims to reach the following objectives:

0 1: - Testing the critical thinking skills of 5th graders in Caraş-Severin county

0 2: - Conceiving, deploying and validating the training program Developing critical thinking by teaching Mathematics in middle school, training course offered by CCD Caraş-Severin, taught toMath teachers in order them to teachMathematicsfor the purpose of developing pupils' critical thinking

0 3: - Monitoring teachers' activity after having attending the training program

0 4:-Comparative analysis of critical thinking skills of the 6th graders in the experimental lot and the control lot

\section{Research hypotheses and variables}

HYPOTHESIS 1.We expect that the educational programelaborated, focused on learning by discovery and problematisation, will significantly contribute to the development of pupils'critical thinking in the experimental lot compared to those in the control lot. 
HYPOTHESIS 2.If the pupils in the experimental group will indeed show critical thinking skills superior to those in the control group, we want to see if these differences are stable over time.

Research independent variable: Teaching Mathematics to 6th graders through the methods of problematisation and learning by discovery

Research dependent variable: Degree of development of pupils' critical thinking

\section{Participants' sample}

In this experiment, a total of 542 pupils were involved, taking into account the results of this test, the geographic distribution, the urban-rural environment, the teaching experience of the teaching staff teaching these pupils, of which 285 were part of the experimental sample and 257 were included in the control sample.

We resume below the presentation of the structure of participants'sample in the pedagogical experiment according to the school of origin:

Table no.1.Structure of theexperimental sample

\begin{tabular}{|c|c|c|}
\hline Sample & College / Middle School & $\begin{array}{l}\text { Number } \\
\text { of pupils }\end{array}$ \\
\hline \multirow{11}{*}{$\begin{array}{l}\text { Experimental } \\
\text { sample }\end{array}$} & National College „C.D. Loga” Caransebes & 52 \\
\hline & National College "Mircea Eliade" Reșita & 16 \\
\hline & National College „Traian Lalescu" Reșita & 28 \\
\hline & Middle School "Ştefan Velovan" Rusca Montană & 9 \\
\hline & Middle School "Trandafir Cocîrlă" Turnu Ruieni & 13 \\
\hline & Middle School Băuțar & 10 \\
\hline & Middle School Domaşnea & 13 \\
\hline & Middle SchoolNo. 1 Otelu-Roșu & 29 \\
\hline & Middle SchoolNo. 2 Reșita & 19 \\
\hline & Middle SchoolNo. 8 Reşjta & 38 \\
\hline & Middle SchoolNo. 9 Reșita & 58 \\
\hline Total & & 285 \\
\hline
\end{tabular}




\begin{tabular}{|c|c|c|}
\hline Sample & College / Middle School & $\begin{array}{l}\text { Numbe } \\
\text { rof } \\
\text { pupils }\end{array}$ \\
\hline \multirow{11}{*}{ Control sample } & National College „Diaconovici Tietz” Resita & 16 \\
\hline & National College "Mircea Eliade" Resitia & 23 \\
\hline & High School „Mathias Hammer" Anina & 33 \\
\hline & High School Hercules Băile Herculane & 14 \\
\hline & Technological High School "Clisura Dunării" Moldova & 68 \\
\hline & Nouă & \\
\hline & Theoretical High School "Eftimie Murgu" Bozovici & 14 \\
\hline & Middle School Armeniş̧ & 23 \\
\hline & Middle School Goruia & 6 \\
\hline & Middle SchoolNo.2 Reșita & 45 \\
\hline & Middle School Tîrnova & 15 \\
\hline Total & & 257 \\
\hline
\end{tabular}

\section{Research instruments used}

In order to be able to analyse complexly and objectively a certain factual state, it is necessary to get the most accurate image,by collecting data on the issue in question. The performance of data collection, the measurement, the processing and the interpretation call for a set of specific research methods and techniques. None of the methods used, however complex and elaborate, would have been sufficient alone to produce the complete data set.

That is why we have resorted to a system of methods which, acting synergistically, have helped to build a clear picture of the current situation.

The method of psycho-pedagogic experiment involves introducing a change in the educational practice, i.e. an independent variable (in our case the method of problematisation and of learning bydiscovery) and in studying its impact on the dependent variable: the degree of critical thinking development.

In our research, the experiment was the main method of investigation used. Testing the working hypothesis involved organizing and conducting a system of didactic experiments, within which we investigated the valences of problematisation and oflearning by discovery in the study of $6^{\text {th }}$-grade Mathematics. 
The study of curriculum documents and other school documents is justified by the need to analyse the written mathematical curriculum, especially the competences proposed by the Ministry of Education regarding the study of Mathematics in middle school, as well as the components of the school curriculum, school textbooks and methodological guides.

This method was also useful for establishing the chapters and themes that will be used in the formative intervention, as well as for the study of the materials representing the pupils' work activities - workbooks, written evaluation papers and note books.

The written evaluation tests were designed to assess as objectively as possible the evolution of the pupils in the experimental and control forms by setting the scores for each item / question, depending on their degree of difficulty.

The selection of the experimental and control forms was carried out after conducting written (initial) evaluation tests, which were meant to determine the overall level of the forms. The teachers of the experimental forms were invited to attend a training course titledDeveloping critical thinking by teaching Mathematics in middle school, training course offered by CCD Caraş-Severin.

During and after the study of the chapters included in the experiment, two evaluation tests were applied, as well as a final one, all these tests being identical for both types of forms. The results obtained at these final tests were compared with those obtained from the same form at the initial tests in order to appreciate the evolution of the forms; the results obtained by the pupils of the experimental forms and those of the pupils in the control forms were also compared to validate the experimental variable introduced. After 3 months, a post-test was conducted to check the time persistence of the outcomes of the psycho-pedagogical experiment

The initial test consisted in a critical thinking test based on the Watson-Glaser model, which aimed at diagnosing pupils' training and sampling them.

The test used was the following:

Problem 1:Passing on the street, we notice that the lights in the house in front of us are on and the TV is on.

Conclusion 1: There is someone in the house.

\begin{tabular}{|c|c|c|c|c|}
\hline $\mathrm{E}$ TRU & $\begin{array}{l}\text { PROBABLETR } \\
\text { UE }\end{array}$ & $\begin{array}{l}\text { INSUFFICIE } \\
\text { NT DATA }\end{array}$ & $\begin{array}{l}\text { PROBABLEFA } \\
\text { LSE }\end{array}$ & $\mathrm{E}{ }^{\text {FALS }}$ \\
\hline
\end{tabular}

Conclusion 2: At least one child lives in the house

\begin{tabular}{|l|l|l|l|l|}
\hline E TRU & \multicolumn{1}{|c|}{ PROBABLETR } & \multicolumn{1}{c|}{ INSUFFICIE } \\
E & UE & PROBABLEFA & \multirow{2}{*}{ FALS } \\
NT DATA & LSE & E \\
\hline
\end{tabular}

Problem2: To get to school faster, my parents take me there by car.

Conclusion 1: Going by car will get me to school faster than by walking.

\begin{tabular}{|c|c|}
\hline YES & NO \\
\hline Conclusion 2: I like to go to school more by car than on foot. \\
\hline YES & NO \\
\hline
\end{tabular}


Problem3: All children like to play.

Conclusion 1: All those who play are children.

\begin{tabular}{|c|c|}
\hline \multicolumn{1}{|c|}{ YES } & NO \\
\hline Conclusion 2: I'm a child, therefore I like to play. \\
\hline YES & NO \\
\hline
\end{tabular}

Problem4: Children's vocabulary increases from 0 words at the age of 8 months to over 2,000 words at the age of six months.

Conclusion 1: No child has learned to speak before the age of six months.

\begin{tabular}{|c|c|}
\hline YES & NO \\
\hline Conclusion 2: At the age of 3, the child uses more than 1,000 words. \\
\hline YES & NO \\
\hline
\end{tabular}

Problem5: Should it be only day, and night should never come?

Argument 1: Yes, because then we would play more

\begin{tabular}{l|l} 
STRONG & WEAK
\end{tabular}

Argument 2: No, because then we would be too tired.

\begin{tabular}{l|l} 
STRONG & WEAK
\end{tabular}

\section{Stages of experimental research}

The experimental research undertaken by us in order to explore certain possibilities of developing critical thinking falls within the category of research aimed at making teaching strategies more efficient by experimenting with new models of action as a researcher directly involved in the didactic process. The research is intended for the practical problems identified by studying the existing curriculum documents and seeks solutions to these issues in their context, allowing the opportunity to promote changes in the professional practice.

The experimental approach developed follows the established structure of pedagogical research, integrating the following action sequences:

- delineating the research problem, capitalizing on the conclusions of the bibliographic study

- $\quad$ conceiving a finding-of-facts preliminary study in the form of a preliminary needs analysis, necessary for the design and realisation of the experimental intervention;

- $\quad$ establishing the purpose and objectives of research;

- investigating the theoretical and applicative premises that will form the basis of the experimental research in se, synthesising the results of the researches existing up to that moment related to the studied problem, as well as the conclusions drawn from the deployment of the fact-finding investigation;

- $\quad$ formulating the general hypothesis and the secondary hypotheses;

- $\quad$ establishing and describing the sample of subjects and compiling the content sample; 
- realisation of the experimental action, observing the stages: preexperimental, experimental and post-experimental;

- $\quad$ synthesising the data obtained by means of pedagogical research methods and tools appropriate to the researched topic;

- analysing, taking over and interpreting the quantitative and qualitative scientificdata obtained by combining qualitative and quantitative analyses;

In order to test the effectiveness of an educational program focused on the use of problematisation and discovery in teaching Mathematics, measured in terms of the development of pupils' critical thinking, we carried out an experimental type of perfecting experiment, which included several stages (preexperimental, of the formativeexperiment, post-experimental, of retesting)

\section{Analysis of the research result}

In order to understand the analysis of the results, I consider it useful to recall the hypotheses of the research:

HYPOTHESIS 1. We expect that the educational programelaborated, focused on learning by discovery and problematisation, will significantly contribute to the development of pupils' critical thinking in the experimental lot compared to those in the control lot - this difference refers to the moments T0 (preintervention) and T1 (post-intervention).

Figure 1 gives details regarding the research

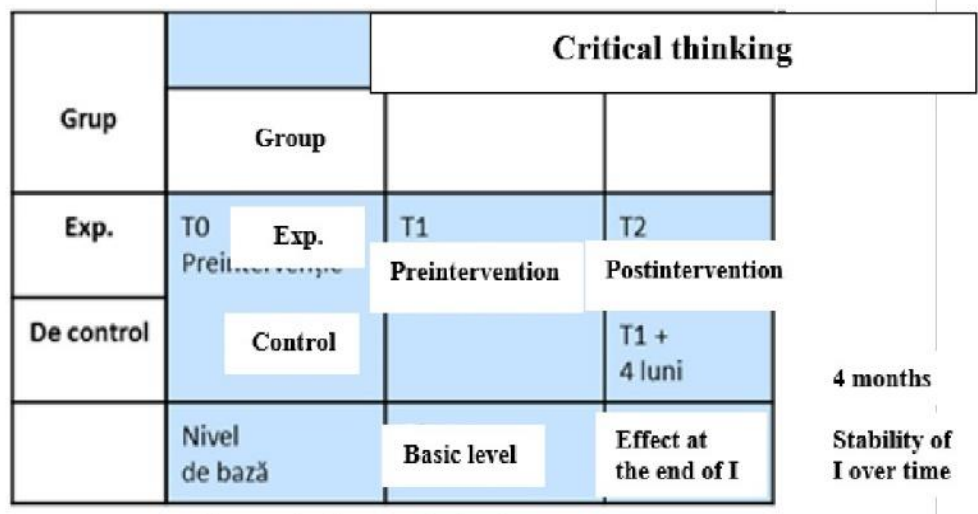

Figure 1: Research design

design and the collected data structure.

HYPOTHESIS 2. If the pupils in the experimental group will indeed show critical thinking skills superior to those in the control group, we want to see if these differences are stable over time. In this sense, we are again testing three possibilities:

HYPOTHESIS $2 \boldsymbol{a}$ - the performances of the experimental group do not change significantly from the moment T1 (post-intervention) at the moment T2 (retest), 
which would indicate that the change is long-lasting and the pupils' performance remains stable over time;

HYPOTHESIS $2 \boldsymbol{b}$ - the performances of the experimental group drop significantly from the moment T1 (post-intervention) to T2 (retest), which would indicate that the change is not long-lasting and the critical thinking level decreases over time;

HYPOTHESIS $2 \boldsymbol{c}$ - the performances of the experimental group increase significantly from the moment T1 (post-intervention) to T2 (retest), which would indicate that the change is not only long-lasting and does not decrease in time, but also that the intervention created a series of critical thinking skills that pupils continue to use to improve their performances, although the intervention is over.

To test hypothesis 1, we used the mixed binary factor ANOVA with Time as the Within Subjects factor (T0, T1) andGroup as the Between Subjects factor (Experimental, Control) andwe can obtain 3 types of outcomes:

1 - main effect ofthe Time factor, which would indicate that there are significant differences in the critical thinking level for the tests applied at different moments.

2 - main effect of the Group factor, which would indicatethat there are significant differences between the two lots, but without providing us with information about the differences between the different moments in time.

3 - Time x Groupinteraction, which is finally the effect that would confirm Hypothesis 1, indicating that there are differences between the two groups at different moments in time.

If we obtain a significant interaction, we shall use anothert test for independent samples in order to compare if there are significant differences between the performance of theexperimental group and of the control group at the post-test, at the moment $\mathrm{T} 1$.

If Hypothesis 1 is confirmed and the experimental group performs better than the control group, we will test Hypothesis 2 . We would use in this case a $t$ test for paired-samples to detect the relationship between the performance at post-intervention and retest within the experimental group.

Another aspect that requires consideration in ANOVA testing is the assumption of sphericity, which represents the condition that the variances (data dispersion under different conditions) of the differences between the possible pairs of the Within factor (e.g. the difference between T0 and T1, or T1 and T2) should be equal. If this condition is not met, there is a risk that the ANOVA results are distorted in a way that would lead to the inflation of coefficient $F$. The testing of the sphericity assumption is done using Mauchy's test (Mauchy, 1940). If the assumptionof sphericity is not met, we shall use Greenhouse-Geisser corrections (Greenhouse \& Geisser, 1959), by which the ANOVA degrees of freedom will be adjusted in order to calculate an appropriatep-value. All the effects will be expressed taking into account the level of statistical significance set at the threshold $\mathrm{p}<.005$. Along with the statistical significance threshold we shall report the increase in the effects obtained (effect sizes, $\eta^{2}$ ). 
The ANOVA results in tests that measure critical thinking are presented in Tables 2 (WithinEffects) and 3 (Between Effects) for the two groups at the moments T0 - Pre-test, T1 - Post-test. Please note that for the analysis of critical thinking, we used only data from thepupils who sat all three testing moments. Consequently, the data from a total of 257 pupils contributed for the experimental group and from 217 pupils for the control group.

The assumption of sphericity was encountered (as it always is when the Within factor has only two levels), and thus there is no need to apply Greenhouse-Geisser corrections. We obtained a significant main effect of the time variable, $\left(F(1,473)=75.48 p<.001, \eta^{2}=.133\right)$,indicating that there are differences between Pre-test and Post-test. The time * group interaction is also significant, $\left(F(1,473)=18.20, p<.001, \eta^{2}=.032\right)$,indicating that there are differences between the two groups at different moments in time. As for the Betweeneffects, the two groups do not exhibit significantly different performances if we do not take into account the effects of the Time factor

Table No. 3.Results for creative thinking, Within effects

\begin{tabular}{|c|c|c|c|c|c|c|}
\hline & $\begin{array}{c}\text { Sum of } \\
\text { Squares }\end{array}$ & $\mathrm{f}^{\mathrm{d}}$ & $\begin{array}{l}\text { Mean } \\
\text { Square }\end{array}$ & $\mathrm{F}$ & $p$ & $\eta^{2}$ \\
\hline Time & 4216 & 1 & $\begin{array}{r}4215 . \\
81\end{array}$ & $\begin{array}{l}75 . \\
48\end{array}$ & $\begin{array}{r}<, 0 \\
01\end{array}$ & $\begin{array}{r}0.1 \\
33\end{array}$ \\
\hline$p^{\text {Time*Grou }}$ & 1017 & 1 & $\begin{array}{r}1016 . \\
73 \\
\end{array}$ & $\begin{array}{r}18 . \\
20 \\
\end{array}$ & $\begin{array}{r}<.0 \\
01 \\
\end{array}$ & $\begin{array}{r}0.0 \\
32 \\
\end{array}$ \\
\hline Residual & 26420 & $\begin{array}{r}4 \\
73\end{array}$ & 55.86 & & & \\
\hline
\end{tabular}

Table No. 4.Results for creative thinking, Between

effects

\begin{tabular}{|l|r|r|r|r|r|r|}
\hline & $\begin{array}{c}\text { Sum of } \\
\text { Squares }\end{array}$ & $\mathrm{f}$ & $\begin{array}{c}\text { Mean } \\
\text { Square }\end{array}$ & F & p & $\eta^{2}$ \\
\hline Group & 1087 & 1 & 1087 & $\begin{array}{r}1.0 \\
68\end{array}$ & $\begin{array}{r}0.3 \\
02\end{array}$ & $\begin{array}{r}0.0 \\
02\end{array}$ \\
\hline Residual & 481583 & 4 & 1018 & & & \\
\hline
\end{tabular}

Given that we have obtained a meaningful interaction term, we shall proceed by further testing whether the two groups have significantly different posttest performances (Hypothesis 1) using ttests for independent samples. This test indicates that the two groups have actually significantly different 
performances at the moment T1 $(t(473)=2.006, p=045)$. In other words, it seems that our hypothesis is confirmed, the pupils in the experimental lot developing higher critical thinking skills as a result of the educational intervention.

Nevertheless, are these abilities stable over time? In order to identify the answer to this question and also to test Hypothesis 2 , we use a $t$ test for clustered samples that compares the performance of pupils in the control group at the moments T1-Post-test and T2-Retest. The result shows that the performance of the experimental group increases significantly at Retest $(t(256)=5.30, p<.001)-$ this effect can be seen inFigure 2. According to Hypothesis 2c, the improvement of critical thinking in the experimental group not only is long-lasting and does not decrease with the passage of time, on the contrary, it even increases over time, possibly because the intervention has created a series of skills that pupils continue to use in order toimprove their critical thinking.

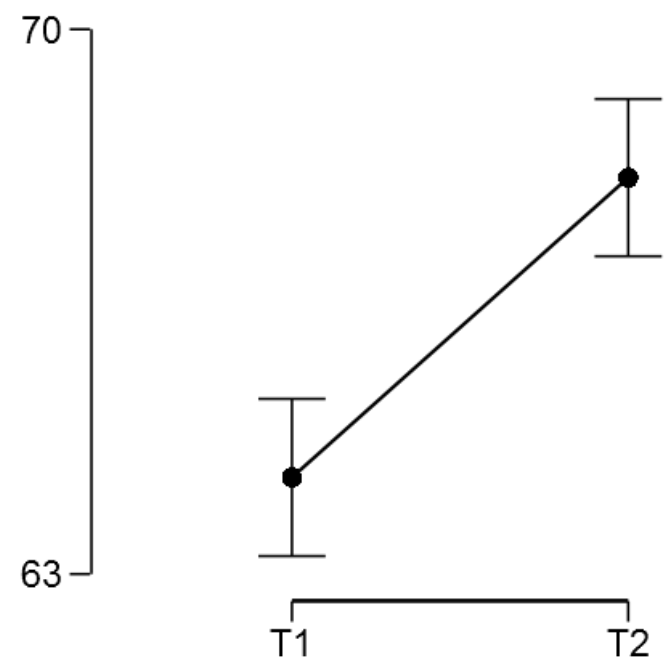

Figure 2 - Critical thinking over time as a result of the educational intervention. T1-Post-test is the moment when the pupils in the control group were tested at the end of the educational intervention. The performanceincrease at the moment T2 - Post-test indicates that the critical thinking skills of the experimental group continue to develop over time after the educational intervention is over. Axis Oy indicates the mean/average results in the tests applied at the two moments in time (measured on a scale from 0 to 100).

\section{General conclusions regarding the research conducted}

The final conclusions were divided into three main categories, namely:

a) General conclusions related to the research (considerations linked to what we set out to accomplish, how we researched and what we achieved);

b) Conclusions on the limits of research (considerations regarding the difficulties and obstacles encountered); 
c) Suggestions for future researches (considerations regarding both our own research path and some recommendations made to Math teachers in order to optimize their teaching performance).

a) What we set out to accomplish (starting point)

The moment of the decision to elaborate this study was when some friends, executives in a programming company, told me they did not understand what we were doing in the educational system, because the graduates of the computer science faculties were not able to make new decisions. They are good specialists, rather good performers, but cannot filter information, cannot weigh alternatives, cannot make reasoned decisions.

Then I began to look in a different manner at what was happening around me, in society, and I began to observe how pupils think and what was there to do. I realized that it is not an isolated problem, but it is a problem of the entire society, namely that it is difficult to make decisions based on a rigorous analysis of the situation and that, most of the time, we make hasty decisions based on what we feel at that moment.

I started studying the works in the literature and I learned only then that what we really lack is critical thinking, and the next question was whether we can measure it, and whether we can contribute to its development.

I discovered that a valid measuring tool for critical thinking is the Watson Glaser test, then I composed items based on this test for the Neutrino contest.

I also asked myself whether the teaching of Mathematics through discovery and problematisation improves pupils' critical thinking skills and I intervened on a number of 542 six-graders in Caraş-Severin county. The selection of the 542 pupils was made taking into account the geographical distribution, the urban / rural percentage, and also the experience of the teachers of those forms, and in the choice of the 6th grade forms the prevailing fact was that it is the grade of the first impact with Mathematics that requires making decisions in solving problems, not just applying solving recipes. Depending on the results at the initial test, the geographical distribution, the urban / rural share, and the experience of the teachers of these forms of pupils, we divided this sample into an experimental lot of 285 pupils and a control lot of 257 pupils. I taught the teachers of the experimental group a training course entitled Developing critical thinking by teaching Mathematics in middle school,and these teachers during the first semester of the 6th grade taught Maths using problematisation and learning by discovery, and also using the approach learned during this training course. At the end of the first semester, when our intervention ended, the pupils of the two samples were tested against the same items, and we obtained significantly better results in the experimental sample. In order to validate the stabilityof these skillsover time, we proceeded to a retesting at the end of the second semester, the results confirming not only that these abilities are preserved, but also that they develop even without continuing the actual intervention.

b) Conclusions related to the research limits (considerations regarding the difficulties and obstacles encountered) 
Like any research, it also had its difficulties.

A first obstacle was the selection of a representative sample of pupils in Caraş-Severin county, and even if we took into account the geographical distribution, the urban / rural percentage, and the experience of the teachers of these forms of pupils, it is possibly that this selection is not the most appropriate.

The second problem was the participation of the pupils in all three measurements of critical thinking skills. In the experiment we included 542 pupils, but only 474 participated in all three measurements, so in order to avoid any misinterpretations we used only those who participated in all three measurements to interpret the results. I keep asking myself whether in the future survey the number of 68 participants lost during the research could not be reduced.

Another question is whether the results obtained it the experimental group are not influenced by the fact that the pupils get familiar during the didactic process with that type of items and not necessarily that their critical thinking skills have progressed. This is a question I still have no answer to.

The fact that at retesting also the pupils in the experimental group get better results than those in the control group could make me believe that these results are due to the development of their critical thinking skills, but I am not sure if their teachers returned to the classical teaching approach or still teach these pupils using learning by discovery and problematisation.

c) Suggestions for future researches (considerations regarding both our own research path and some recommendations made to Math teachers in order to optimize their teaching performance).

My research does not stop here, I want to study whether teaching through problematisation and learning by discovery also improves the school performance of pupils; in this respect I collected the test results, the school average grades and I shall follow the results of the national evaluation of the pupils involved in the research. I will also monitor the results of these pupils in Physics and Chemistry to see if they are influenced by the manner of teaching Mathematics.

I would be delighted if these methods should be used predominantly by Mathematics teachers, and by other teachers as well, because the pupils' results were significantly better.

\section{References:}

Bocoş M., (2013). Instruire interactivă. Editura Polirom, Iaşi

Bernstein, D.A.(1995), A Negotiation Model for Teaching Critical Thinking, Retrieved from https://journals.sagepub.com/doi/10.1207/s15328023top2201 7

Greenhouse, S. W., \& Geisser, S. (1959). On methods in the analysis of profile data. Psychometrika, 24, 95-112.

Fisher, A. (2001). Critical Thinking, Cambridge University Press, The Pitt Building, Trumpington Street, Cambridge, United Kingdom. Retrieved from http://assets.cambridge.org/97805210/09843/sample/9780521009843ws.pdf 
Halpern, D. F. (2002). Thought and knowledge: An introduction to critical thinking. Routledge.

Mauchly, J. W. (1940). Significance test for sphericity of a normal n-variate distribution. The Annals of Mathematical Statistics, 11(2), 204-209.

Mervis, C. B., Kistler, D. J., John, A. E., \& Morris, C. A. (2012). Longitudinal assessment of intellectual abilities of children with Williams syndrome: Multilevel modeling of performance on the Kaufman Brief Intelligence Test-Second Edition. American Journal on Intellectual and Developmental Disabilities, 117(2), 134-155.

Meyers, C. (1986). Teaching students to think critically. San Francisco, CA: Jossey-Bass Publishers, 1-10

Ordinul Ministrului Educaţiei şi Cercetării nr.3.393 din 28.02.2017

Vasile, M. (2014). Introducere în SPSS pentru cercetarea socială..., Editura Polirom, Iaşi 